\title{
EL PRETÉRITO PERFECTO COMPUESTO EN RELATOS DEL CASTELLANO DE ACOLLA (JUNÍN)
}

\author{
Yrma Doris García Rojas* \\ Universidad Católica Sedes Sapientiae \\ yrma.garcia.r@upch.pe
}

Fecha de recepción: agosto de 2019 Fecha de aceptación: diciembre de 2019

Resumen: Este artículo científico da cuenta del comportamiento morfosintáctico del pretérito perfecto compuesto (PPC) en relación con el pretérito perfecto simple (PPS) en el castellano de Acolla. El objetivo del estudio fue determinar si la frecuencia de uso del PPC era mayor al de PPS en relatos orales del pasado de esta variedad dialectal. Se trabajó sobre la base de la producción narrativa de 75 niños y niñas de seis años, monolingües del castellano. La estrategia Mi mascota favorita (MMF) resultó ser bastante efectiva para el acopio de información, insumo útil en la conformación del

Yrma Doris García Rojas es magíster en Lingüística por la Universidad Nacional Mayor de San Marcos, autora de la tesis Estructuras del pretérito en relatos orales en el Castellano de los niños de seis años del distrito de Acolla. Con estudios culminados de Maestría en Docencia e Investigación en Educación Superior por la Universidad Peruana Cayetano Heredia y un diplomado en Gestión y Diseño Curricular en Educación Superior Universitaria por la misma universidad, Investigadora interesada en estudios sobre la variedad de castellano andino peruano y autora de artículos académicos como Génesis del Castellano Andino de Acolla y Barlow's corpora analysis as an ESAP reading comprehension strategy. Cuenta con una vasta experiencia en docencia universitaria y formación inicial docente. 
corpus lingüístico. Para el cálculo de la frecuencia absoluta y relativa de las formas verbales involucradas, se utilizó el programa informático Windows AntConc, versión 3.2.4. Los resultados señalan que en el castellano de Acolla, la frecuencia de uso del PPC es significativamente mayor a la del PPS tal como ocurre en otras variedades de castellano andino. Se concluye que en el castellano de Acolla, el PPC goza de mayor preferencia en narraciones que describen eventos temporalmente ocurridos no solamente en un pasado lejano sino también remoto.

Palabras Clave: Pretérito perfecto compuesto, pretérito perfecto simple, temporalidad verbal, castellano/español andino.

\section{THE PRESENT PERFECT IN STORIES OF SPANISH OF ACOLLA (JUNÍN)}

\footnotetext{
ABSTRACT: The current research deals with the morphosyntactic behavior of the present perfect in relation to the past simple tense in Spanish of Acolla. The objective was to determine whether the frequency of use of the present perfect is higher than the one of the past simple in past events stories. Our research is based on seventy five Spanish-speaking six-yearold children's oral narrative production. Data collecting for the linguistic corpus was through the strategy named by the author as My favorite pet. This procedure proved to be highly effective for our goals. For the relative and absolute frequency analysis of the involved verbal perfect forms, data were entered on Windows AntConc, 3.2.4 software version. The research
} 
findings indicate that in Acolla's Spanish, the present perfect use frequency is significantly higher than the one of the past simple. This result is similar to other Andean Spanish dialects. The conclusion is that in Acolla's Spanish past event narratives, the present perfect is the prevalent verbal form over the past simple.

KeYwords: Present perfect, past simple, tense, Andean Spanish.

\section{Introducción}

7 estudio sobre la variación dialectal del castellano goza de gran interés tanto en España como en países de Hispanoamérica, siendo el tema referido al pretérito perfecto compuesto (PPC) en relación con el pretérito perfecto simple (PPS) el más favorecido pero también el más controvertido. Valls (2017) y Hurtado (2009) destacan que en el español de España, exceptuando algunas zonas, y en el de América en su conjunto, existe mayor preferencia por el pretérito perfecto simple que por el compuesto.

Partiendo de la teoría lingüística y desde el punto de vista aspectual, ambas formas verbales son perfectivas y desde la perspectiva temporal, las dos expresan anterioridad respecto al punto del habla. La diferencia radica en que el pretérito simple expresa un tiempo absoluto, y el pretérito compuesto, un tiempo relativo (Bello, 1847 citado por Hipogrosso, 2004; RAE, 2010). Es decir, en el caso del pretérito simple, la desvinculación de la acción respecto al punto del habla es definitiva. Por el contrario, el "perfecto 
compuesto nos da la idea de un presente ampliado hacia el pasado" (Emilio Alarcos, 1970, citado por Valls, 2017).

En Latinoamérica, desde una perspectiva diatópica, estas formas verbales presentan ciertas particularidades regionales tanto en su distribución cuantitativa (Hurtado, 2009) como en su uso y valor semántico. En Ecuador y Perú, por ejemplo, pese a que en la estimación global de frecuencias de cada país se destaca el predominio del pretérito perfecto simple (PPS), se atestigua la supremacía del PPC sobre el PPS en las zonas andinas. Este hecho no significaría ninguna novedad sino fuese porque se presenta como un fenómeno lingüístico que contraviene la normativa estándar de la Real Academia Española (RAE). Este desajuste gramatical se hace evidente en textos narrativos orales, en especial, cuando el hablante hace referencia a acontecimientos acaecidos en el pasado, hechos desvinculados totalmente del presente y por consiguiente, culminados y en los que el uso del PPS sería el más apropiado.

En el castellano de Acolla se hace evidente tal desavenencia lingüística. Las muestras extraídas de una entrevista a un niño de la zona así lo delatan: 1) "... dice el gato le machucaba al, al conejo. Le haciba morir, el gato feliz se comiba, vinió su mamá, y del gato le molestó y se ha comido; 2) (Ayer) He sacau papa, 3) (La semana pasada) He dado fiesta, en ahi, mi mamá hamos ido después, después hemos veniu. Hemos iu mirar, después ya nos hemos vuelto ya, y 4) (El año pasado) Fiesta (ha) habido carnaval, todo ban botau, caramelo, (ha) habiu safacasa todo, después, mm acá abajo, después ya nos hamos veniu ya, hamo terminau de botar caramelo, hamos veniu ya. ... mi mamá tamien ha chapado cosas. Frente a preguntas conteniendo adverbios de tiempo en pasado es de esperar que el hablante aluda al pasado 
haciendo uso del pretérito simple (PPS) antes que el pretérito compuesto (PPC).

Expertos como Jara (2011, en consonancia con Bybee, Perkins \& Pagliuca, 1994; Fleischman, 1983; Harris, 1982) atribuyen la incursión del PPC al avance del proceso de gramaticalización del perfecto compuesto como un fenómeno natural interno del sistema verbal que se inicia con el latín vulgar. El hecho incide en el carácter polisémico del compuesto, presentando así una pluralidad de significados, funciones y valores en las diferentes variedades dialectales del español. Por otro lado, lingüistas como García Tesoro y Jang (2018) sostienen que la aparición del PPC en los relatos orales obedece más bien a instancias externas como el contacto de lenguas, en este caso, entre el español y las lenguas aborígenes como el quechua y aimara.

Esta influencia es reconocida como una transferencia lingüística que genera en el perfecto compuesto funciones novedosas como aquella de evidencialidad (Jara, 2011, basada en Schumacher, 1975; Bybee et al., 1994, Escobar, 1997; Klee y Ocampo, 1995; Sánchez, 2004) y subjetivación (Jara, 2011, citando a Traugott, 1989, 1995); de relevancia espacial (Jara, 2011, citando a Escobar, 1997) y de modalidad (Bustamante, 1991). El caso de evidencialidad, por ejemplo, se explica cuando el hablante bilingüe de quechua y español recurre al uso del pretérito perfecto compuesto español para aludir a la fuente de información, rasgo gramatical característico de la lengua quechua.

El presente artículo está dedicado a dar cuenta de los hallazgos obtenidos en el análisis lingüístico del pretérito perfecto compuesto (PPC) en el castellano de Acolla. El informe se enmarca en el método cuantitativo. Se conforma un corpus lingüístico con los relatos orales de niños acollinos de 
seis años de edad y monolingües del español. El objetivo es llegar a establecer que el pretérito perfecto compuesto es la forma o estructura verbal de mayor preferencia sobre el pretérito perfecto simple en la narrativa oral acollina.

\section{Marco Teórico}

\subsection{Estado de la cuestión del PPC y PPS en América}

La Tabla 1 detalla la distribución relativa y absoluta del grado de empleo del pretérito perfecto simple y pretérito perfecto compuesto en países de Hispanoamérica. Se evidencia una ausencia de homogeneidad cuantitativa y se destaca la supremacía global del primero sobre el segundo, es decir del PPS sobre el PPC. Al interior de cada país, la preponderancia va en el mismo sentido a excepción de Bolivia. Ecuador, por ejemplo, acusa cifras de $75 \%$ y $25 \%$; Perú, 68\% y 32\% y Bolivia, $43.2 \%$ y 56.8\%, respectivamente (Hurtado, 2009). Dicho de otro modo, de manera global, en Perú y Ecuador se favorece significativamente el uso del pretérito simple sobre el compuesto pero en Bolivia sucede ligeramente lo contrario. 
EL PRETÉRITO PERFECTO COMPUESTO EN RELATOS DEL CASTELLANO DE ACOLLA (JUNÍN)

Tabla 1

Frecuencia Relativa y Absoluta del Perfecto Simple y del Perfecto Compuesto en Hispanoamérica

\begin{tabular}{|c|c|c|c|c|c|}
\hline \multirow[b]{2}{*}{ País } & \multicolumn{2}{|c|}{ Perfecto simple } & \multicolumn{2}{|c|}{ Perfecto compuesto } & \multirow{2}{*}{$\begin{array}{c}\text { Relación entre } \\
\text { ambos }\end{array}$} \\
\hline & Número & Porcentaje & Número & Porcentaje & \\
\hline Argentina & 1.133 & 85,3 & 195 & 14,7 & 5,8: 1 \\
\hline Bolivia & 881 & 43,2 & 1.158 & 56,8 & $0,8: 1$ \\
\hline Chile & 2.297 & 81,9 & 507 & 18,1 & $4,5: 1$ \\
\hline Colombia & 1.178 & 69,8 & 509 & 30,2 & $2,3: 1$ \\
\hline Costa Rica & 1.596 & 75,9 & 506 & 24,1 & $3,1: 1$ \\
\hline Ecuador & 1.260 & 41,8 & 424 & 14,0 & $3,0: 1$ \\
\hline Guatemala & 220 & 67,5 & 106 & 32,5 & $2,1: 1$ \\
\hline México & 2.354 & 87,6 & 334 & 12,4 & $7.0: 1$ \\
\hline Paraguay & 670 & 90,8 & 68 & 9,2 & $9,8: 1$ \\
\hline Perú & 1.427 & 68,0 & 673 & 32,0 & $2,1: 1$ \\
\hline Puerto Rico & 934 & 76,9 & 281 & 23,1 & $3,3: 1$ \\
\hline $\begin{array}{l}\text { R. Domini- } \\
\text { cana }\end{array}$ & 872 & 74,6 & 297 & 25,4 & $2,9: 1$ \\
\hline Venezuela & 1.739 & 73,4 & 630 & 26,6 & $2,8: 1$ \\
\hline TOTALES & 16.561 & 74,4 & 5.688 & 25,6 & $2,9: 1$ \\
\hline $\begin{array}{l}\text { Tomado de “ } \\
\text { inclusión o ex } \\
\text { Filológicos, } 44\end{array}$ & $\begin{array}{l}\text { perfecto s } \\
\text { ión del al } \\
95 \text {. }\end{array}$ & ple y el pe & $\begin{array}{l}\text { ecto com } \\
\text { iación," p }\end{array}$ & $\begin{array}{l}\text { uesto en His } \\
\text { or S. Hurtad }\end{array}$ & $\begin{array}{l}\text { panoamérica: la } \\
\text {, 2009, Estudios }\end{array}$ \\
\hline
\end{tabular}


Jara (2011), en un estudio sobre el castellano de Lima, identifica el reparto de pretéritos en narraciones de experiencia personal $(\mathrm{PEN})^{1}$ con resultados similares al de Hurtado sobre la idea de la preponderancia del simple sobre el compuesto. De un total de 1,776 frecuencias, 833 (46.9\%) le corresponden al pretérito perfecto simple (PPS), 161 (9.1\%) al pretérito perfecto compuesto (PPC), 66 (3.7\%) al presente narrativo, $79(4.4 \%) \mathrm{al}$ pluscuamperfecto y 637 (35.9\%) al imperfecto. Jara (citando a Howe, 2006; Jara Yupanqui, 2006; Rojas-Sosa, 2008 y Rodríguez Louro \& Jara Yupanqui, 2011) concluye que la distribución de las formas pretéritas en textos narrativos de experiencia personal en el habla limeña evidencia la supremacía numérica del simple sobre el compuesto.

En un estudio posterior respecto al castellano amazónico peruano, Jara y Valenzuela encuentran que la distribución de las formas pretéritas de la variedad jeberina contrasta significativamente con la del castellano de Lima. La "incursión del PP en contextos del PS es tan avanzada que sus frecuencias sobrepasan a las del PS” (2013, p. 57). Así, el castellano de Jeberos reporta un 69.16\% (713/1031) para la forma compuesta y un 30.84\% (318/1031) para la simple. En suma, el número de oraciones cuya estructura contiene PPC es mayor que el de PPS pese a tratarse de relatos que corresponden a eventos acaecidos en el pasado lejano.

Por otro lado, Hurtado (2009) no solo resalta la vigencia de las formas del pretérito perfecto simple (CANTÉ) y el pretérito perfecto compuesto (HE CANTADO), sino además sostiene que los valores semánticos que se les otorga en el español americano y el español peninsular no presentan coincidencias.

$1 \quad$ PEN = Personal Experience Narrative (siglas en inglés). 
Una de las diferencias dialectales más pronunciadas entre grandes partes de Hispanoamérica y de España es la relativa al uso del perfecto simple y el perfecto compuesto, siendo la oposición constituida por ambas formas uno de los aspectos más debatidos, controvertidos e intrigantes de la morfosintaxis del verbo español. (p. 94)

En el castellano andino de Ayacucho, Esquivel (2013), al igual que Jara y Valenzuela (2013), advierte una frecuencia considerable del compuesto sobre el pretérito simple. García Tesoro y Jang (2018), respecto al castellano del Cuzco y el distrito de Chincheros, señalan que de un total de 1892 oraciones, 1024 corresponden al PPC y 868 al PPS en una relación relativa de $54.12 \%$ y $45.88 \%$, respectivamente. Los autores destacan que "la frecuencia de uso del PPC es muy elevada" (p. 14) en las variedades dialectales cusqueñas.

\section{Caso del Castellano de Acolla}

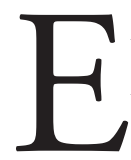

1 nombre de castellano de Acolla ${ }^{2}$ es en alusión a un distrito de la provincia de Jauja en la región Junín. Tal distrito se encuentra ubicado en el ámbito geográfico del Valle de Yanamarca, subzona del norte del valle de Mantaro (Robles \& Martínez, 2004) en la sierra central del Perú. Los límites de su territorio comprenden Acolla cercado, pequeños pueblos y anexos como Sacas, El Tingo, Tingo Paccha, Tambo Paccha, Yanamarca, Pachascucho y Chuquishuari.

2 Nombre que tiene su origen en la palabra compuesta quechua «Aqu-lla» y cuyo significado nos remite a una cantidad de piedrecitas y cascajos. 


\subsection{Metodología}

El estudio del castellano de Acolla se desarrolla desde un enfoque cuantitativo. Se trabajó la frecuencia relativa y absoluta del uso del pretérito perfecto compuesto y pretérito perfecto simple.

\subsubsection{Diseño}

En lo que respecta al corpus Acollino, líneas arriba se declaró que la investigación sobre esta particular variedad dialectal de castellano se circunscribe al enfoque cuantitativo por la determinación de la frecuencia del PPC sobre el PPS, siendo por ello de tipo descriptivo relacional.

\subsubsection{Participantes}

Los participantes son alumnos de seis años de edad que cursaban el primer grado de primaria en el momento de la investigación. La muestra para este estudio se caracteriza por ser etnodemográfica y de tipo no probabilístico por conveniencia. Por tratarse de un número reducido de niños, se estimó que todos tuvieran la misma oportunidad de conformar la muestra.

El grupo de estudio estuvo constituido por una población de 81 niños y niñas monolingües del castellano y perteneciente a familias de agricultores igualmente hablantes del castellano. Se consideró las 13 escuelas públicas tanto del ámbito territorial de Acolla cercado, como poblaciones y anexos que conforman el distrito del mismo nombre según el Padrón de Centros y Programas Educativos: 2013 (MINEDU). Finalmente, los datos que se utilizaron para la conformación del corpus acollino corresponden a 75 niños que estuvieron presentes en el momento de las entrevistas y que 
representan al 92.6\% del total de registrados en el padrón de las escuelas en el 2013.

\subsubsection{Recolección de datos}

El acopio de datos se dio en dos fases. La primera fase fue de exploración (2012) y la segunda, de investigación propiamente dicha (2013).

La etapa exploratoria nos permitió tener indicios sobre el castellano acollino en el habla de los niños. Además, pudimos corroborar el monolingüismo de los participantes, información que resultó crucial para el análisis. Igualmente, esta etapa sirvió para el reconocimiento de la zona, el contacto con las autoridades educativas y la identificación del grupo de estudio. Asimismo, nos permitió prever las limitaciones que dificultarían la etapa investigativa.

La etapa exploratoria también resultó clave para la validación de la entrevista semiestructurada de tipo demográfico. Pese a que un porcentaje de preguntas estuvo orientado a generar relatos de experiencia personal en el pasado, la producción narrativa de los informantes resultó ser escasa y por consiguiente los datos resultaron insuficientes para la investigación.

En la fase investigativa, ideamos una nueva estrategia que la hemos denominado Mi mascota favorita (MMF). Bajo la consigna Cuéntame qué le pasó a tu mascota, los niños de Acolla debían formular relatos concernientes a eventos, sucesos y acontecimientos ocurridos en puntos, intervalos o periodos temporales anteriores y distantes del momento de la entrevista. La estrategia se amoldó a la siguiente dinámica:

El entrevistador invita a los niños a que se sienten en una mesa alrededor suyo. Con la ayuda de un dispositivo de plastilina al que se le ha 
dado la forma de un perro, empieza contándoles la historia de una mascota ficticia. El entrevistador provee pedazos de plastilina a los niños y les persuade a recrear su mascota favorita y luego los insta a producir su propio cuento. El entrevistador trata de mantener la continuidad de los relatos con preguntas como ¿Qué le pasó a tu mascota?, ¿Qué más?, ¿Y luego?, ¿Por qué? ¿Qué pasó?, ¿Qué hiciste?, ¿Cómo fue eso?, ¿Para qué?, ¿Cuándo fue eso?

Las narraciones se grabaron con la ayuda de un dispositivo digital de voz COBY CXR190-4G y fueron luego transcritas como textos narrativos siguiendo las pautas de Risco.

\subsubsection{Conformación del corpus del castellano de Acolla}

A partir de la transcripción ortográfica o "transliteración” (Listerri, 1997) se logró conformar 58 narraciones que representaran estructuras discursivas consistentes, con sentido lógico e inteligibilidad. Se prosiguió con la codificación de las oraciones bajos ciertos parámetros y criterios y apoyados en explicación lingüística (Villayandre, 2010). En este caso se utilizó caracteres numéricos y alfabéticos para la codificación. Se tomó en cuenta oraciones simples en cuya estructura se evidenciaba tiempos verbales de pretérito perfecto e imperfecto, simples y compuestos, tal como se verá en el siguiente apartado.

\section{Resultados}

\subsection{Análisis del corpus del Castellano de Acolla}


En la variedad dialectal del castellano de Acolla, se acusa la presencia de la estructura verbal de tiempo pretérito perfecto compuesto o PPC en 1 351 oraciones, tal como se muestra en la Figura 1.

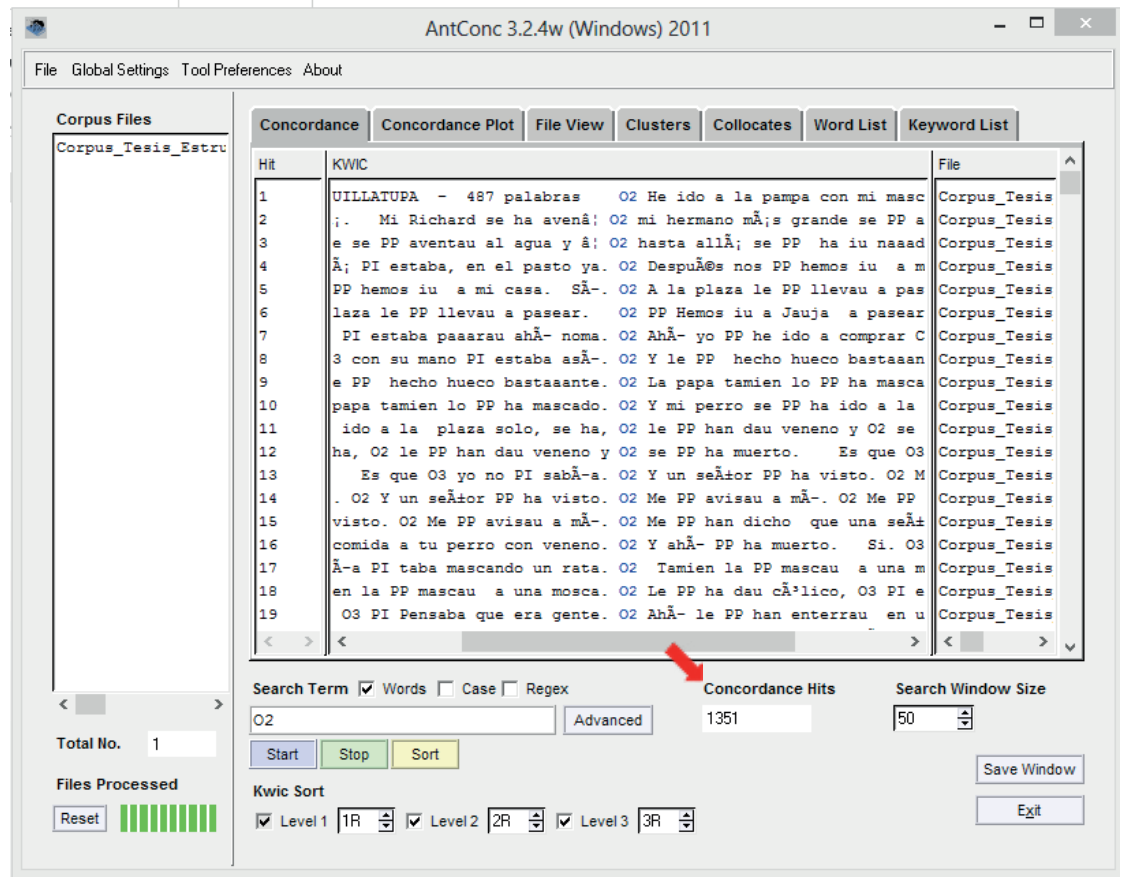

Figura 1. Número de frecuencia de oraciones en PPC en el corpus del castellano de Acolla con la ayuda del programa AntConc 3.2.4.

Por otro lado, la Tabla 2 evidencia la distribución integral de las distintas estructuras oracionales en el corpus acollino. De un total de 3 337 oraciones, 1351 cuentan en su estructura con el pretérito perfecto compuesto, el cual se traduce en $40,48 \%$. Le sigue el presente simple, con 
1052 oraciones que representan el 31,52\%; luego el pretérito imperfecto, con 574 oraciones que hacen $17,20 \%$ y el pretérito perfecto simple, con 187 oraciones que se traducen en el 5,60\% del total. Existe otras formas pretéritas representadas en mínimos porcentajes.

\section{Tabla 2}

Distribución del Sistema Verbal en el Corpus del Castellano de Acolla

\begin{tabular}{|c|c|c|c|c|}
\hline $\begin{array}{l}\text { Código } \\
\text { oracional }\end{array}$ & $\begin{array}{l}\text { Categoría } \\
\text { oracional }\end{array}$ & $\begin{array}{l}\text { Código } \\
\text { verbal }\end{array}$ & $\begin{array}{l}\text { Número } \\
\text { de } \\
\text { frecuencias }\end{array}$ & $\begin{array}{c}\text { Porcentaje } \\
\%\end{array}$ \\
\hline $\mathrm{OO}$ & $\begin{array}{l}\text { Oraciones en } \\
\text { tiempo presente } \\
\text { simple y presente } \\
\text { continuo y/o } \\
\text { progresivo }\end{array}$ & --- & 1052 & 31,52 \\
\hline $\mathrm{O} 1$ & $\begin{array}{l}\text { Pretérito perfecto } \\
\text { simple } \\
\text { (canté) }\end{array}$ & $\mathbf{P}$ & 187 & 05,60 \\
\hline $\mathrm{O} 2$ & $\begin{array}{l}\text { Pretérito perfecto } \\
\text { compuesto } \\
\text { (he cantado) }\end{array}$ & PP & 1351 & 40,48 \\
\hline $\mathrm{O} 3$ & $\begin{array}{l}\text { Pretérito } \\
\text { imperfecto } \\
\text { (cantaba) }\end{array}$ & PI & 574 & 17,20 \\
\hline
\end{tabular}




\begin{tabular}{|c|c|c|c|c|}
\hline $\mathrm{O} 4$ & $\begin{array}{c}\text { Pretérito } \\
\text { pluscuamperfecto } \\
\text { (había cantado) }\end{array}$ & PL & 17 & 0.51 \\
\hline O5 & $\begin{array}{c}\text { Pretérito } \\
\text { imperfecto } \\
\text { continuo } \\
\text { (estaba cantando) }\end{array}$ & ---- & 137 & 4,10 \\
\hline O6 & $\begin{array}{l}\text { Pretérito anterior } \\
\text { (hube cantado) }\end{array}$ & PA & 00 & 00 \\
\hline O7 & $\begin{array}{c}\text { Subjuntivo } \\
\text { presente } \\
\text { (cante) }\end{array}$ & ---- & 04 & 0,12 \\
\hline O8 & $\begin{array}{c}\text { Voz Pasiva de } \\
\text { pretérito } \\
\text { (estaba amarrado) }\end{array}$ & ---- & 06 & 0,18 \\
\hline O9 & $\begin{array}{l}\text { Futuro perfecto } \\
\text { (habrá ido) }\end{array}$ & ---- & 09 & 0,27 \\
\hline Total de Os & $\begin{array}{c}\mathrm{OO}+\mathrm{O} 1+\mathrm{O} 2 \\
+\mathrm{O} 3+\mathrm{O} 4+\mathrm{O} 5 \\
+\mathrm{O} 6+\mathrm{O} 7+\mathrm{O} 8 \\
+\mathrm{O} 9\end{array}$ & ---- & 3337 & $100 \%$ \\
\hline
\end{tabular}

Comparativamente, se colige de la Tabla 3 la distribución del PPC en relación al PPS. Se tiene que de 3337 oraciones, 1538 corresponden a los pretéritos perfectos, y de ellas, 1351 le pertenecen al PPC y 187 al PPS, haciendo un $87.84 \%$ y $12.16 \%$, respectivamente. Se demuestra así que en el castellano acollino existe una superioridad significativa en la frecuencia de uso del pretérito compuesto sobre el simple. 


\section{YRMA DORIS GARCÍA ROJAS}

\section{Tabla 3}

Distribución de las formas pretéritas perfectas PPS y PPC en el corpus del castellano de Acolla

Código

Categorías

Frecuencia

Frecuencia

absoluta

relativa

$\%$

\section{PPS}

$\mathrm{O} 1$

Pretérito perfecto

187

12,16

simple

(canté)

PPC

命

$\mathrm{O} 2$

Pretérito perfecto

1351

87,84

compuesto

(he cantado)

$\mathrm{O}$

$\mathrm{O} 1+\mathrm{O} 2$

1538

$100 \%$ 


\section{FRECUENCIA RELATIVA ENTRE LAS FORMAS DE PPCY PPS EN EL CASTELLANO DE ACOLLA}

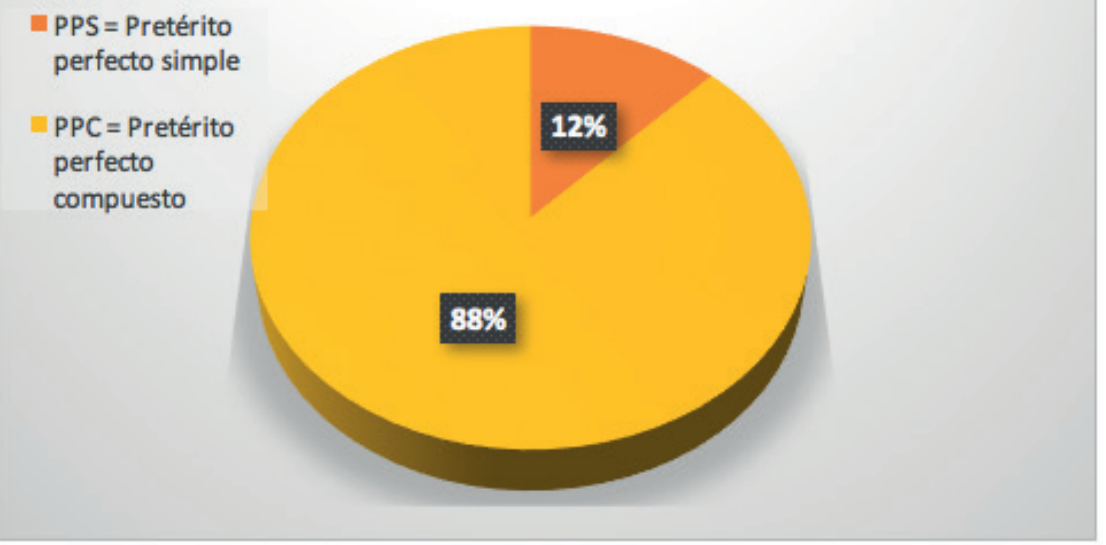

Figura 2. Frecuencia relativa entre el pretérito perfecto compuesto (PPC) y el pretérito perfecto simple (PPS) en el castellano de Acolla.

De los cuadros estadísticos se deduce que la relación entre PPC y 


\section{Discusión}

$\mathrm{E}$

n cuanto al análisis cuantitativo, la herramienta tecnológica informática de Windows AntConc, versión 3.2.4. (Anthony, 2011) se comporta como un soporte útil para el cálculo con resultados precisos de frecuencias y distribución de datos lingüísticos previamente codificados y categorizados.

De los resultados se puede colegir que las frecuencias de usos del PPC en el castellano acollino se aproxima al del castellano amazónico de Jeberos (Jara \& Valenzuela, 2013), pues en esta variedad, el PPC (pretérito perfecto compuesto) excede al PPS (pretérito perfecto simple) en una relación de $69,16 \%$ y 30,4\%, respectivamente, de un total de 1031 oraciones. Similar situación sucede en el castellano de Ayacucho, el castellano de Chincheros y castellano de Cuzco.

Por otro lado, los datos del castellano de Acolla se muestran contrarios a los del español de Lima (Jara, 2011). Los porcentajes de esta variedad presentan una distribución inversa a los del español de Acolla, con un $85 \%$ para el PPS y un 15\% para el PPC de un total de 2687 oraciones.

En un inicio, el estudio se vio expuesto a serias dificultades en lo que respecta a la obtención de datos. La producción oral de los informantes fue muy escasa para el propósito del estudio. Los expertos al referirse a la competencia comunicativa de la población infantil de zonas rurales, sostienen que aquella está asociada a factores internos y externos, entendiéndose a los primeros como de tipo neurológico, psicoafectivo y cognitivo; y a los segundos, de tipo lingüístico (Harley, 2009), geográfico, sociológico (Espín, 1987) y grado de escolaridad de los padres (Ramírez, 2004).

Frente a esta dificultad, la necesidad de cambio de estrategia para la recolección de datos era vital. La propuesta MMF resultó ser efectiva, ya que 
se logró que los participantes construyan narraciones sobre hechos pasados de manera fluida y productiva, obteniéndose así el insumo apropiado para la conformación del corpus acollino. Dicho de otro modo, el desarrollo de las narraciones en la fase investigativa se dio con mayor fluidez y consistencia.

La RAE establece las funciones de las formas temporales del PPC y PPS a nivel oracional; y desde la perspectiva discursiva, Labov y Walezky (1997) y Silva-Corvalán (1999) sostienen que en las construcciones narrativas la forma verbal por excelencia es el PPS. Sin embargo, se produce una desavenencia entre lo que establece la teoría y lo que sucede en la realidad, en este caso, representada por el castellano acollino. Valls (2017) sostiene que los usos de PPC y PPS reflejan una clara oposición de funciones, aunque con ciertos matices y que por ello no se podría establecer generalizaciones.

En este estudio es importante resaltar el monolingüismo en castellano de los niños informantes. Pese a que la comunidad acollina está vinculada étnicamente a ancestros de la cultura Wanka ${ }^{3}$ cuya lengua es el Quechua Wanka (Plan de Desarrollo Concertado del distrito de Acolla 2011 2021), los niños utilizan la lengua hispana como medio de comunicación. Cerrón-Palomino (2003) asegura que el uso del quechua por parte de los adultos se mantiene vigente en el Valle del Mantaro, solo que en privado y en la intimidad familiar. La literatura revisada conduce mayormente a casos de estudio del pretérito perfecto en hablantes bilingües de castellanoquechua o castellano-aimara, y un número reducido, a casos de hablantes monolingües del castellano. Ello nos lleva a señalar que nuestra investigación resulta ser un aporte a la lingüística del castellano andino peruano hablado por monolingües.

3 Grupo étnico invadido por los incas en 1460 que tuvo a la variedad quechua wanka como lengua de comunicación. 


\section{Conclusiones}

T os resultados de este estudio conducen a corroborar la hipótesis planteada. Existe una significativa preponderancia del pretérito perfecto compuesto (PPC) sobre el pretérito perfecto simple (PPS) en el castellano de Acolla hablado por niños y niñas monolingües de seis años de edad. La frecuencia relativa es de 7 a 1, con porcentajes que van entre $87.84 \%$ y $12.16 \%$, respectivamente.

La supremacía numérica del PPC respecto al PPS en narraciones orales del castellano de Acolla se asemeja a la de otras variedades dialectales de las áreas andinas del Perú como Ayacucho, Chincheros y Cuzco, y el castellano de Jeberos de la Amazonía. En referencia al castellano de Lima, los resultados son opuestos. En esta variedad, el número de incidencias de pretérito simple sobrepasa al del pretérito compuesto. El dialecto capitalino está más en consonancia con el castellano de Hispanoamérica, en el que el PPS aventaja al PPC.

Queda como tarea pendiente el estudio cualitativo del PPC en la variedad acollina. Estamos seguros que resultará interesante develar lo que el paradigma verbal ofrece a la teoría lingüística del castellano andino peruano. 


\section{REFERENCIAS}

Anthony, L. (2011). AntConc, versión 3.2.4 [software para la investigación lingüística, realiza búsqueda de palabras o frases en contexto en un corpus de textos]. Recuperado de https://tinyurl.com/pfnug4p

Bustamante, I. (1991). El presente perfecto o pretérito perfecto compuesto en el español quiteño. Lexis, 15(2), 195-231.

Cerrón-Palomino, R. (2003). Castellano Andino: Aspectos sociolingüísticos, pedagógicos y gramaticales. Lima, Perú: Fondo Editorial de la Pontificia Universidad Católica del Perú.

Espín, J. (1987). El lenguaje del niño de seis a ocho años: Elementos que la integran. Revista de Logopedia, Foniatría y Audiología, 7(2), 93-103. Recuperado de https://tinyurl.com/yafqnuey

Esquivel, J. (2013). El pretérito perfecto en el castellano andino. Ponencia presentada en el VIII Congreso Internacional de Lexicología y Lexicografía en Homenaje a Martha Hildebrandt Pérez Treviño de la Academia Peruana de la Lengua, Lima, Perú.

García Tesoro, A. I., \& Jang, J. (2018). El pretérito perfecto compuesto en el español andino peruano: usos innovadores y extensión a contextos de aoristo. Forma y Función, 31(1), 93-123.

Jara, M. (2011a). Funciones discursivas y gramaticalización del pretérito perfecto compuesto en el español de Lima (pp. 95-118). John Benjamins Publishing Company. 5 de mayo. Recuperado de www. benjamins.com 


\section{YRMA DORIS GARCÍA ROJAS}

Jara, M. (2011b). Present perfect usage in Peruvian Spanish and perfective readings in narratives. Revista Internacional de Lingüistica Iberoamericana, 2(18), 213 - 236.

Jara, M., \& Valenzuela, P. (2013). El uso del perfecto en secuencias narrativas en el español peruano amazónico: el caso de Jeberos. Lexis, 37(1), $33-70$.

Harley, T. A. (2009). Psicología del lenguaje: de los datos a la teoría. Madrid, España: McGraw-Hill/Interamericana de España.

Hipogrosso, C. (2004). El Sistema Verbal Español. Revista de la Educación del Pueblo, 94 mayo-junio.

Hurtado, S. (2009). El perfecto simple y el perfecto compuesto en Hispanoamérica: la inclusión o exclusión del ahora de la enunciación. Estudios Filológicos, (44), 93-106. Recuperado de: http://www. redalyc.org/pdf/1734/173413835006.pdf

Labov, W., \& Waletzky, J. (1997). Narrative analysis: Oral versions of personal experience. Journal of Narrative and Life History, 7(1-4), 3-38.

Listerri, J. (1997). Transcripción, etiquetado y codificación de corpus orales. Madrid, España: Instituto Cervantes.

Ministerio de Educación. (2013). Unidad de Gestión Educativa Local Jauja, Gobierno del Perú. Padrón de Centros y Programas Educativos.

Plan de Desarrollo Concertado del Distrito de Acolla, Jauja, Gobierno Regional de Junín, 2011-2021. Recuperado de https://pdfslide.net/ documents/2-pdc-acolla-contenido.html 
Ramírez, E. (2004). Educación para la población rural en Brasil, Chile, Colombia, Honduras, México, Paraguay y Perú. Proyecto FAOUNESCO-DGCS/ITALIA-CIDE-REDUC.

Real Academia Española. (2010). Nueva gramática de la lengua española. Manual. Madrid, España: Espasa Libros.

Real Academia Española. (2011). Nueva gramática básica de la lengua española. Bogotá, Colombia: Editorial Planeta Colombiana.

Robles, R., \& Martínez, M. (2004). Sociedad y tradiciones en el valle de Yanamarca. Revista de Antropología 2(2), 191-250.

Silva-Corvalán, C. (1998-1999). Aspecto verbal: de la oración al discurso. Boletin de Filología de la Universidad de Chile, 37(2), 1157-1169. Recuperado de https://boletinfilologia.uchile.cl/index.php/BDF/ article/view/21682/22993

Valls, C. (2017). Usos del pretérito perfecto simple y compuesto en la lengua española. Un análisis comparativo de distintas variedades (tesis de pregrado, Universidad de Barcelona, España).

Villayandre, M. (2010). Aproximación a la Lingüistica Computacional (tesis doctoral. Departamento de Filología Hispánica y Clásica, Universidad de León, España). 
